\title{
Contexto da população Ribeirinha do Município de Belém
}

\author{
Context of the riverside population of the Municipality of Belém
}

Contexto de la población ribereña del Municipio de Belém

\section{Resumo}

Esse artigo aborda os aspectos históricos de uma população ribeirinha que vive nas ilhas do município de Belém. Relata também, de forma resumida, o processo de construção da vida cotidiana dessas pessoas e como foi bastante dolorosa e violenta a vivência desses com a presença dos portugueses e de outros povos que aportaram na Amazônia. Os invasores precisavam de mão de obra escrava para poder explorar e expandir as terras que eles tomaram como suas dentro da região e os índios, por sua vez, acabavam sendo uma mão de obra habilitada para andar na floresta, nos rios e ainda fácil de serem escravizados. O estudo busca mostrar que a preservação da cultura ribeirinha demonstra a resistência de um sistema ecológico e de tradições sociais trazidas de pai para filho e como esse costume está fortemente relacionado ao movimento de expansão da economia extrativista produzido nas ilhas do município de Belém. E a conservação dessa comunidade sobrepõe o sistema capitalista de reproduzir no espaço-tempo.

Palavras-chave: População ribeirinha; Segregação; Políticas públicas; Floresta amazônica; População cabocla.

\begin{abstract}
This article addresses the historical aspects of a riverine population that lives on the islands in the municipality of Belém. It also tells, in a summarized way, the process of construction of the daily life of these people and how painful and violent was their experience with the presence of the Portuguese and other people that arrived in the Amazon. The invaders needed slave labor to be able to explore and expand the lands they took as their own in the region, and the Indians, in turn, ended up being a labor force qualified to walk in the forest, in the rivers, and still easy to be enslaved. The study seeks to show that the preservation of the riverside culture demonstrates the resistance of an ecological system and of social traditions brought from father to son, and how this custom is strongly related to the expansion movement of the extractive economy produced on the islands of the city of Belém. And the conservation of this community overlaps the capitalist system of reproducing in space-time.
\end{abstract}

Keywords: Riverside population; Segregation; Public policy; Amazon rainforest; Caboclo population.

\section{Resumen}

Este artículo aborda los aspectos históricos de una población ribereña que vive en las islas del municipio de Belém. También relata, de forma resumida, el proceso de construcción de la vida cotidiana de estos pueblos y cómo fue bastante dolorosa y violenta su experiencia con la presencia de los portugueses y otros pueblos que llegaron a la Amazonia. Los invasores necesitaban mano de obra esclava para poder explorar y expandir las tierras que tomaron como propias dentro de la región y los indios, a su vez, terminaron siendo una mano de obra calificada para andar en la selva, en los ríos y aún fácil de ser esclavizada. El estudio pretende mostrar que la preservación de la cultura ribereña demuestra la resistencia de un sistema ecológico y de las tradiciones sociales traídas de padres a hijos y cómo esta costumbre está fuertemente relacionada con el movimiento de expansión de la economía extractiva producida en las islas del municipio de Belém. Y la conservación de esta comunidad se superpone al sistema capitalista para reproducirse en el espacio-tiempo.

Palabras clave: Población ribereña; Segregación; Políticas públicas; Selva amazónica; Población de caboclo. 


\section{Introdução}

A análise a ser desenvolvida no trabalho, refere-se ao processo sócio histórico da população ribeirinha do município de Belém do Pará, como dominação do povo europeu e a economia transformou toda uma cultura estabelecida no ambiente natural que seria a população indígena.

Entre as discussões, torna-se substancial discorrer sobre a sequência da história que os europeus invadiram e tomaram os índios como escravos se organizou como donos da terra dentro do município. Para assim entendermos a organização atual dos ribeirinhos e o modo de vida dessas comunidades que vivem as margens dos rios amazônicos.

O objetivo do artigo é demonstrar o processo histórico do surgimento da população ribeirinha que vive às margens dos rios amazônicos, e como esse processo trouxe impacto na sociedade belenense. E assim demonstrar como essa população, que apesar de pequena, ainda busca espaço para poder viver com dignidade, com seu modo de vida ecologicamente sustentável.

\section{Metodologia}

O artigo constitui-se numa revisão bibliográfica/ histórica do desenvolvimento do município de Belém e o modo de vida e costumes da população ribeirinha. Consiste também nos dados quantitativos de quantos blocos de ilhas consistem no município de Belém e quantas pessoas vivem nessas ilhas.

A metodologia empregada neste estudo, é de natureza exploratória. De acordo com Pereira (2018), uma pesquisa configurasse como exploratória, quando é possível obter um contato maior com o problema em questão, através de uma investigação em estudos de caso.

Assim o artigo está dividido em três partes, onde na primeira faz-se um resgate histórico de Belém e apresentação da sua cultura ribeirinha. Na segunda parte trata-se de relatar história da Econômica no município de Belém e como essa expansão econômica modificou o espaço e a sociedade. E na última parte, será abordado Dado acerca das Ilhas no Município de Belém, expondo as informações de população e organização de blocos de ilhas.

\section{História da População Ribeirinha das Ilhas do Município de Belém}

A origem sócio espacial dos ribeirinhos na Amazônia se deu por estar relacionada ao contexto histórico da população chamada "cabocla", que habitavam a região norte, e eram ameríndios. Com a chegada dos europeus na Amazônia, mais especificamente no município de Belém, as condições socioambientais da região influenciaram a maioria dos habitantes dessa nova cidade que era formada por indígenas que foram os principais trabalhadores entre meados do século XVII e final do século XVIII, devido serem tratados como seres humanos “incultos”.

Para Ribeiro (1995, p.99), estes eram escravizados pelos imigrantes por serem "um trabalhador ideal para transportar cargas ou pessoas por terras e por águas para o cultivo de gêneros e o preparo de alimentos, para a caça e a pesca". Além do mais, ele tinha um "papel preponderante nas guerras aos outros índios e aos negros quilombolas", estes foram bastante explorados pelo conhecimento que os mesmos tinham da região, fato que propiciou o crescimento da economia, conforme interesse dos invasores.

O projeto civilizatório-cristão nesse processo foi essencial para incluir a população indígena no costume dos novos habitadores. Depois de toda a imposição religiosa dos índios surgiu o "índio genérico" homogeneizado culturalmente, pronto para a escravidão o êxodo econômico, desta nova população descende o ribeirinho ameríndio atual. 
Os índios tinham algumas habilidades desse povoado como a facilidade de locomoção pelas florestas, as variedades de costumes agrícolas e conhecimentos de elementos da natureza, vegetações, pecuária, etc. O costume bem usado até hoje, consiste na agilidade de movimentação e transporte de peixes e outros alimentos pelos rios, e também para fuga e outros motivos. Todos esses conhecimentos chamaram a atenção dos europeus e de vários estudiosos.

Pesa ainda hoje o fato de a população ribeirinha ser resultado histórico de uma miscigenação "decretada" pelo Estado lusitânico. O ribeirinho nega, as suas raízes indígenas (mesmo tendo uma noção de sua indianidade), o que não impede que ele continue sendo discriminado como caboclo, (Arenz, 2000).

Os ribeirinhos é uma junção dos colonos, índios, com os imigrantes, conseguiram resistir à transformação históricoeconômica do município de Belém, conseguindo manter os eixos principais das culturas dos seus antepassados indígenas, na agregação a natureza com a extração de vegetal, frutas e outros, na vivencia social de pequenas comunidades e também na pratica religiosa.

Através desse processo (aldeamento dos religiosos) foi surgindo uma população nova, herdeira da cultura tribal no que ela tinha de fórmula adaptativa a floresta tropical. Falava uma língua indígena (o nheengatu) muito embora esta se difundisse como um dialeto das civilizações, aprendida de brancos e mestiços.

O conhecimento dos índios auxiliava no reconhecimento das plantas, os bichos da mata, as águas e as formas de vida aquáticas, os duendes e as visagens, segundo conceitos e termos das culturas originais. Provia sua subsistência através de roçado de mandiocas, de milho e de algumas dezenas de outras culturas tropicais, também herdadas dos índios. Do mesmo modo como os povos originários caçavam, pescava, coletava pequenos animais, frutos e tubérculos. Navegava pelos rios com canoas e balsas, construíam suas rancharias e as provia de utensílios segundo as velhas técnicas tribais (Ribeiro, 1997).

Nessa perspectiva, Santos (2014), mostra que a relação do ribeirinho com o rio é de grande importância na estrutura da comunidade e no seu trabalho na região, "se é um rio que sofre influência das marés, se há grandes correntezas, ou separa uma sociedade ribeirinha de uma cidade, estas características são determinantes para o modo de vida dos ribeirinhos". O que evidência de que o rio dita o modo de vida de cada população que mora às suas margens, assim como os índios que viviam nelas, e por muito tempo viveu sabendo aproveitar o ciclo biótico da várzea que segue o ritmo de enchente e vazamento anuais do rio. O autor retrata de que "a vida dos ribeirinhos do Baixo Amazonas é completamente diferente da vivência daqueles que habitam próximo a Belém" que vão adquirindo influências do modo de vida urbana da grande cidade, embora permaneçam com sua cultura, hábitos e costumes.

Para Meirelles (2015), muitos processos de transformação marcaram historicamente a população ribeirinha e pode ser resumida em quatro etapas são elas:

A conquista e a consolidação da dominação portuguesa (1616-1639)

A Aase dos aldeamentos controlados pelos religiosos (1653-1759) e do diretório da administração civil (17591798),

$>$ A fase da resistência e repressão (1798-1853) e, finalmente.

$>$ A época da integração e globalização (desde 1853).

Todas essas modificações de narração abrangem o período da fundação da cidade de Belém (1616) até os meados do início do ciclo da borracha (1879 e 1912). Que foram marcados por muitas lutas e mortes principalmente pelos índios que não aguentavam a exploração que era imposta e se revoltavam e acabando sendo dizimados violentamente. 


\subsection{Organização espacial e econômica a partir dos anos 1960}

As distribuições espaciais das terras foram feitas de forma injusta e discriminatória deixando os índios e ribeirinhos de fora na divisão de lotes e gerando um monopólio da terra, que nem, o Estado adquire uma solução coerente para superá-lo. Esse mesmo monopólio trouxe progresso de forma não sustentável e sem se importar com a cultura e tradições da população indígenas e ribeirinhas em relação a terra e a natureza em geral, assim, reportando a Harvey (2013), que afirma que "os valores de uso na terra e sobre a terra são dons gratuitos da natureza", portanto, pode se dizer que é de pleno domínio da população, no caso, os ribeirinhos.

O autor ainda reforça que "a produtividade física da força de trabalho varia segundo circunstância naturais, que são monopolizáveis e não reprodutíveis”, o que deixa claro a exclusão social desses trabalhadores que sempre manusearam a terra para o seu sustento e moradia. Tudo isso não muda o fato de que os ribeirinhos continuaram sendo, a ultima fase da historia amazônica, que somente entra em percepção quando entra em ameaças ambientais devido o garimpo, a mineração e a caça predatória.

No mesmo ano o governo do estado do Pará se auto promoveu para se desenvolver, com promessas de emprego e oportunidade de vidas melhor, várias pessoas de outras regiões, querendo aproveitar a oportunidade e conseguir através de seu trabalho, desenvolver a região norte e incorporá-la no centro do país. A Amazônia mostrada como um lugar quase sem habitação seria uma ótima oportunidade de exploração e desenvolvimento.

O que levou a um aglomerado migratório de muitas pessoas de todas as partes do país principalmente do Nordeste, eles buscavam promessas positivas, porem o governo não aguentou o impacto negativo acelerado, dessa grande aglomeração que trouxeram junto com elas, os problemas sociais e urbanos para a região, que se intensificou e ampliou com o crescimento populacional, todo o problema se deu pela falta de investimento na infraestrutura municipal, ficando assim a cidade deficiente desses serviços e de infraestrutura básica.

O fracasso do programa de desenvolvimento da borracha foi devido vário causa as arvore ficavam muito distantes umas das outras, e assim trouxe dificuldade para a extração do látex, e também a estrada nos seringais da Amazônia requeria grandes conhecimentos de percursos do terreno, e do processo de extração da borracha selvagem. Geralmente os trabalhadores eram inexperientes, trazidos de regiões totalmente diferente do Norte, ou seja, incapacitado a se adaptar no caminhar da floresta como relata Ribeiro (1995, p. 322).

Assim é que o seringal se implanta como uma empresa desvinculada da terra. Seu elemento é o rio, no qual o homem não se fixa como povoador, mas apenas se instala como explorador até o esgotamento dos seringais. Então, vai adiante com seus próprios meios: a canoas, o barracão de mercadorias e o livro de débito que mantém presos os seringueiros a seu patrão. Em cada seringal, um grupo de caboclos amazônicos exerce as funções de mestres que desasnam os recém-chegados, os "brabos". Ensinam a identificar a seringueira, a sangrá-la-á diariamente sem afetar-lhe a vida, a colher o látex e a defumá-lo-ão cuidadosamente para formar as bolas de borracha (Ribeiro, 1995:322).

As mudanças da expansão econômica trouxeram muitos impactos para a população ribeirinha, essas pessoas com pouca ou nem uma instrução não conseguiram acompanhar a mudança agressiva, impactando profundamente as culturas regionais da Amazônia. Nunca desejado e nem inserido no sistema econômico, mas sempre necessário quando se precisavam de mão de obra barata, informal e sempre disponível.

No mesmo período do início de século XX que houve a metropolização do município de Belém, forte crescimento econômico e uma urbanização extensiva, também ocorreu as mudanças da fase do período da borracha. Além do grande fluxo fluvial, os conflitos sociais intensificaram devido à falta de moradia e planejamento urbano na cidade. 
Diante do cenário do século XX, os ribeirinhos estabeleceram moradias nas ilhas do município de Belém, entre outras próximas. Hoje em dia, devido a região metropolitana de Belém possuir características bem singulares em relação aos rios que moldam em torno da construção da cidade e pelas proximidades, oferece condições econômicas favoráveis, porém ainda apresenta problemas mediantes ao crescimento desordenado da região.

Ao longo da década de 1960, houve uma nova dinâmica que se institui de forma muito profunda, ligando essa continuação de formação de território. A construção da rodovia Belém-Brasília foi uma forma de transformar definitivamente a relação Belém com as demais regiões do país. Deixando notório seu processo de urbanização e expansão territorial típico de um processo de urbanização de fronteira impulsionada pelas estradas estaduais e federais.

Todo esse processo de estímulo e implantação de projetos de porte econômico como o crescimento de madeireiras e agropecuárias, irão modificar de maneira definitiva a estrutura de intacta dos ares e de cidades fluviais e principalmente os ribeirinhos.

\subsection{História Econômica no município de Belém}

Em 1639, no município de Belém, houve uma expedição liderada pelo militar Teixeira e o bandeirante Maciel e através dela foi consolidada do espaço físico e a submissão dos povos indígenas, devido a nova colônia precisar de uma extensiva mão de obra, usar os índios como escravos era uma solução rentável, pois os negros não conheciam a pratica do extrativismo e nem a floresta, sendo uma mão de obra cara e menos útil. Usando-os para vários projetos agrícolas, mesmo não dando certo o sistema mercantilista com base agrária. Assim colocaram um conotativo de "nativo" para os moradores regionais que extraiam as drogas do sertão como: castanha do Pará, óleos e extratos vegetais, cacau e outros, que foi essencial para a economia local.

Ao decorrer dos anos os religiosos e a igreja se inseriam nas aldeias para dominar a mão de obra escrava indígenas com a desculpa de integração do projeto de homogeneização cultural e assim detinham poderes ilimitados. Em aproximadamente no ano de 1690 começou a reduzir a influência dos religiosos na economia regional e na mão de obra, pois existiam algumas drogas do sertão como: fumo, anil, cacau, canela e outros, que precisavam ser cultivadas no interior no estado do Pará e comercializada e centralizada na capital dele. Por essas questões abriu uma perspectiva de consolidação definitiva da empresa colonial estatal na Amazônia. Em outubro do mesmo ano foi revogado a inserção dos religiosos a pagar impostos.

Outra lei emitida em fevereiro de 1693, explicitou que o poder temporal dos religiosos estava exercendo nos aldeamentos não os livrasse da obediência as autoridades civis e eclesiásticas ordinárias. Em novembro de 1694, finalmente foram delimitadas as áreas de atuação para cada congregação. A jurisdição temporal dos religiosos foi ainda mais reduzida em janeiro de 1699, quando foi declarada por lei que ela não valeria nos territórios das capitanias hereditárias estabelecidas entre 1632 e 1637. No mesmo ano foram intimidados os religiosos que retivessem nas repartições índios aldeados "produtivos" causando, assim prejuízos aos colonos (Meireles Filho, 2015).

Depois da investida fracassada de introduzir o sistema agrário em meado do século XVII, e o afastamento do domínio econômico regional a companhia de comercio tornou-se o agente principal do governo possuindo o monopólio comercial. Assim fora realizado uma estratégia de tentar estimular a economia amazônica baseando em na agricultura e no extrativismo, formando várias roças comuns e fabricas do sertão, ou seja, produtos do sertão sendo plantado em grandes escalas.

Os rios que percorrem a Amazônia formaram uma integração com o processo de urbanização da Região Metropolitana de Belém (RMB), assim influenciou no modo de vida dos ribeirinhos e das questões econômicas e sócias, principalmente devido ao dinamismo extrativista e através de grandes exportações da época. 
O surgimento do movimento da Cabanagem, que ocorreu em 1835, foi uma rebelião popular que provocou diversas mudanças naquele período do século XIX e principalmente para a Amazônia e a região norte. Foram uma revolta popular bastante violenta, devido a vários conflitos na época, e a fuga dos indígenas por causa das disputas territoriais e conflitos internos políticos e econômicos.

Outro processo histórico e econômico: O ciclo da borracha, um dos acontecimentos marcantes, que aconteceu entre os anos 1853 e 1870, e impulsionou o crescimento econômico da Amazônia, assim como originou mudanças no modo de vida da população indígena e dos demais imigrantes. Devido aos conflitos, os ribeirinhos foram excluídos do processo de crescimento econômico no final do século XIX, pois fugiram para os interiores da floresta e não se envolveram nas inovações que a produção da borracha proporcionou na época. Isso afetou o desenvolvimento desses povos tradicionais e ainda afeta.

Desde os primeiros engenhos de cana de açúcar e arroz no século XVIII e XIX, com a introdução da exploração do indígena (que foi extinta na região) e de escravos, trazidos da África a partir do Século XVIII e que reuniram-se, principalmente no Vale do Rio Acará, Guamá e Moju, seguido pelo breves ciclos da borracha (1890-1914 e 1940-1945), a moderna ocupação da Belém Insular ocorre no início do século XX, após a débâcle da borracha, pela lenta ocupação das margens por extrativistas (Filho (2015).

$\mathrm{Na}$ época do ciclo da borracha houve toda a fragilidade das atividades dos ribeirinhos e que levaram a exploração do seu trabalho. Segundo Arenz (2000), chama a atenção, pois, que os "trabalhadores por conta própria" predominam na Região Norte em comparação com as demais regiões do Brasil. Isso se deve ao fato de a "economia regional repousar nos latifúndios extrativos e pecuários, funcionando a agricultura como uma atividade restrita ao autoconsumo".

As atividades agroextrativistas e agrícolas, são a base para as comunidades ribeirinhas, porém também existem outros fatores importantes que influenciaram na economia e modo de vida dos ribeirinhos, os processos históricos e econômicos, sendo um deles: a industrialização. O processo de industrialização viabilizou progressos para a região Norte e o governo contribuiu para a integração física economicamente dessa região com as demais, impulsionou o avanço de novas rodovias e acessos, com grandes projetos, para facilitar a locomoção que não seria feita apenas pelos rios.

Esse fluxo migratório que aconteceu de outros locais para a Amazônia, aumentou os insumos paras as indústrias e o fluxo do comércio, com isso, a cidade de Belém virou uma grande metrópole, a segunda maior da região. Essas mudanças não afetaram apenas os habitantes locais, mas também para as comunidades próximas, assim como os ribeirinhos.

A Região Metropolitana de Belém, hoje ocupa aproximadamente 30\% da população do estado do Pará e teve seu crescimento econômico e social relacionado aos rios que percorrem a Amazônia oriental, pois os fluxos fluviais, além de outros fatores, formaram uma integração com o processo de urbanização e metropolização do município de Belém.

As dinâmicas econômicas que ocorreram no município, de fenômenos chamados de processos urbanos de implosão e explosão da urbanização da cidade, foram oriundas em muitos aspectos pela migração da Amazônia Oriental, ou seja, gerando grande fluxo de pessoas para a cidade de Belém desde os anos 60. E com isso, geraram problemas urbano-rural, com a carência do planejamento regional e falta de saneamento básico para todos os moradores.

Devido esse crescimento acelerado da população e dos ribeirinhos, esses aspectos influenciaram o modo de vida dos habitantes, e a economia, com a dinâmica agroextrativista que tem como base fundamental para economia do belenense.

A cidade de Belém transformou-se, ao longo de séculos, num espaço de forte diversidade de atividades econômicas de comércio e de serviços, apoiada por uma miríade de pequenos núcleos urbanos espalhados no vasto território amazônico. Neste sentido, seu mercado de trabalho, seguindo essa relação estrutural e histórica ao estilo path dependency (baseado na tradição e nos compromissos já firmados), explica que ainda hoje a capital do estado, além das funções inerentes a essa condição, mantenha tão elevado grau de interligação com as cidades ribeirinhas da região (Cardoso, 2015:33). 
Research, Society and Development, v. 10, n. 3, e14610313173, 2021

(CC BY 4.0) | ISSN 2525-3409 | DOI: http://dx.doi.org/10.33448/rsd-v10i3.13173

A dependência e vivência que o ribeirinho tem com o rio e a floresta está além do puramente econômico ele transfigura este ambiente e absorve a transfiguração na sua vida (Ribeiro, 2010).

A comunidade ribeirinha do município de Belém se caracteriza por núcleos familiares que vivem predominantemente de uma economia regional da pesca e do agro extrativismo vegetal. Essas comunidades sofrem com a exclusão econômica e ocorre a desigual social, os impactos ambientais e econômicos. As edificações têm formatos simples, são compostas por palafitas nas margens dos rios, e os ribeirinhos utilizam barcos e canoas, para locomoção e sobrevivência (Figuras 1, 2 e 3).

Figura 1. Ribeirinhos.

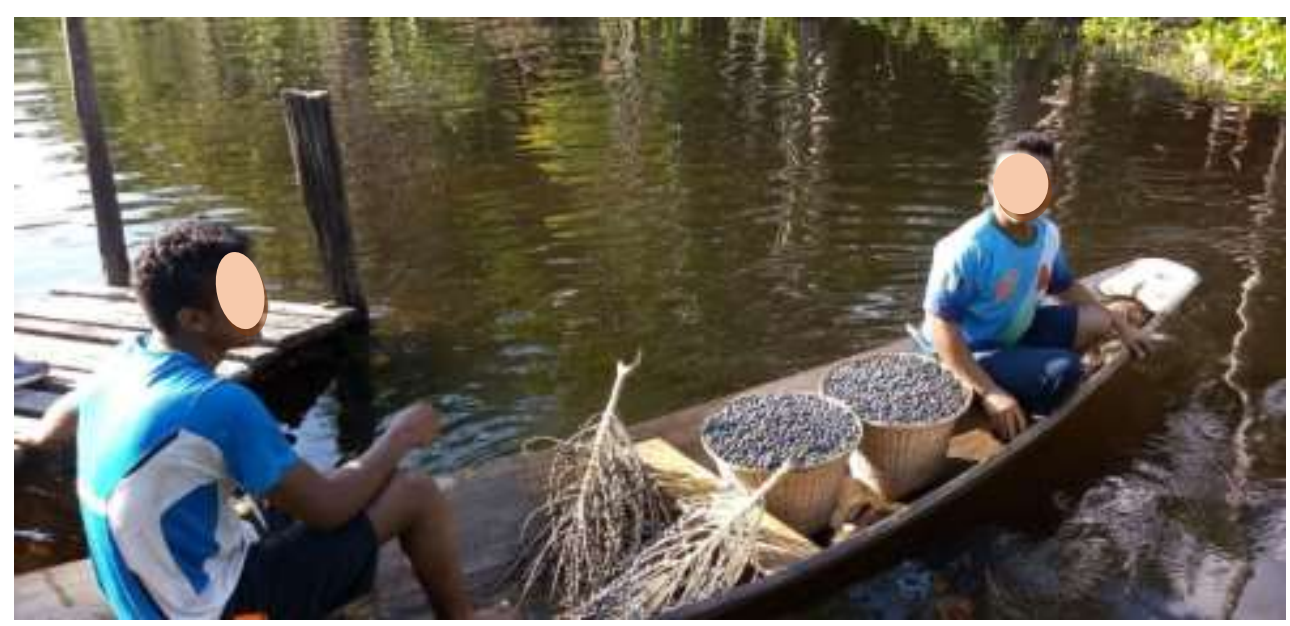

Fonte: http://bemdiverso.org.br/not\%C3\%ADcias?_plantas=cj2uq8zzv007umzv24p3k3wog

Figura 2. Palafitas nas margens dos rios.

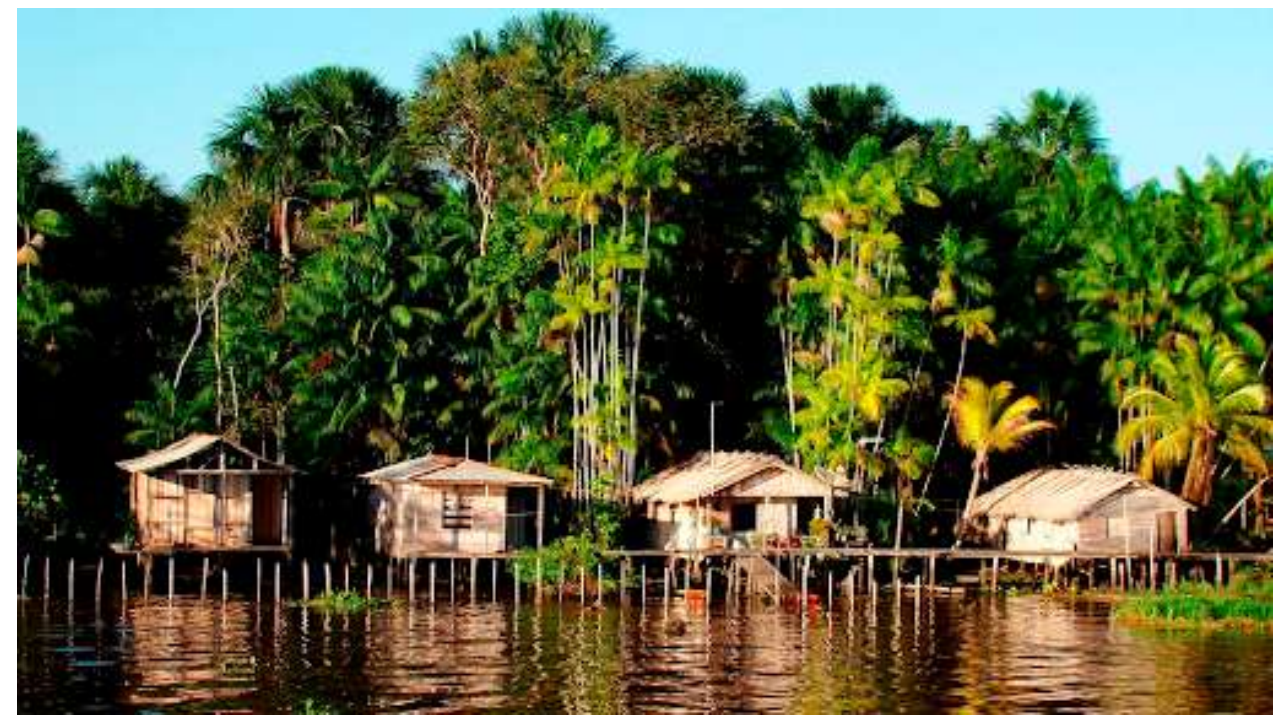

Fonte: https://peabiru.org.br/2016/03/11/comunidades-ribeirinhas-ampliam-acoes-em-busca-de-um- 
Figura 3. Ribeirinhos.

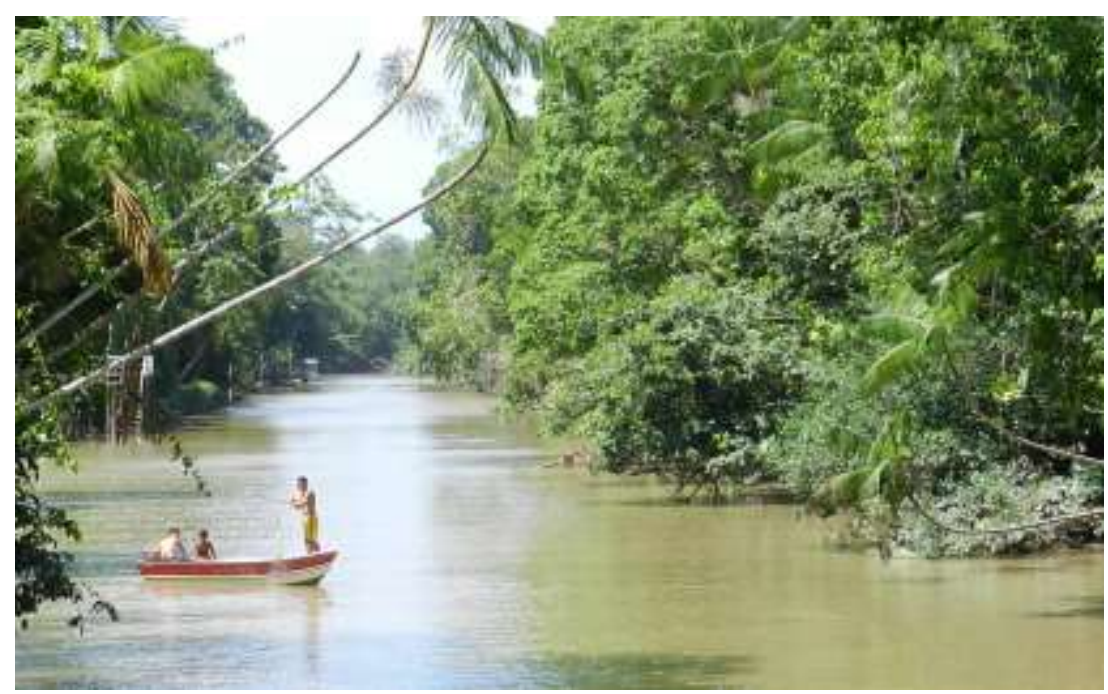

Fonte: www.folha.uol.com.br/turismo/2016/01/1731505-comunidades-ribeirinhas-do-entorno-de-belem-recebem-turistas-em-casa.shtml

Os problemas enfrentados economicamente nessas comunidades, têm sido um desafio para a população, mas cabe ao poder público e a novas perspectivas de vida e de ajuda para contribuir com as melhorias necessárias. A valorização dos produtos regionais é primordial, para assim aprimorar os recursos financeiros, os costumes e diminuir o descaso com as atividades extrativistas.

\subsection{Dados acerca das ilhas no município de Belém}

O município de Belém está localizado à margem direita do rio Amazonas na foz do tipo estuário. O sítio urbano está coberto por extensa rede de cursos d'água devido à localização na confluência da baia do Guajará com a foz do rio Guamá, verificando-se a presença de igarapés, várzeas e terra firme, sendo a área marcada por um corolário composto de um grande número de ilhas (figura 4), de fato trata-se de uma insularidade, constituída de aproximadamente 39 ilhas, como mostra o mapa.

Figura 4. Localização das ilhas de Belém.

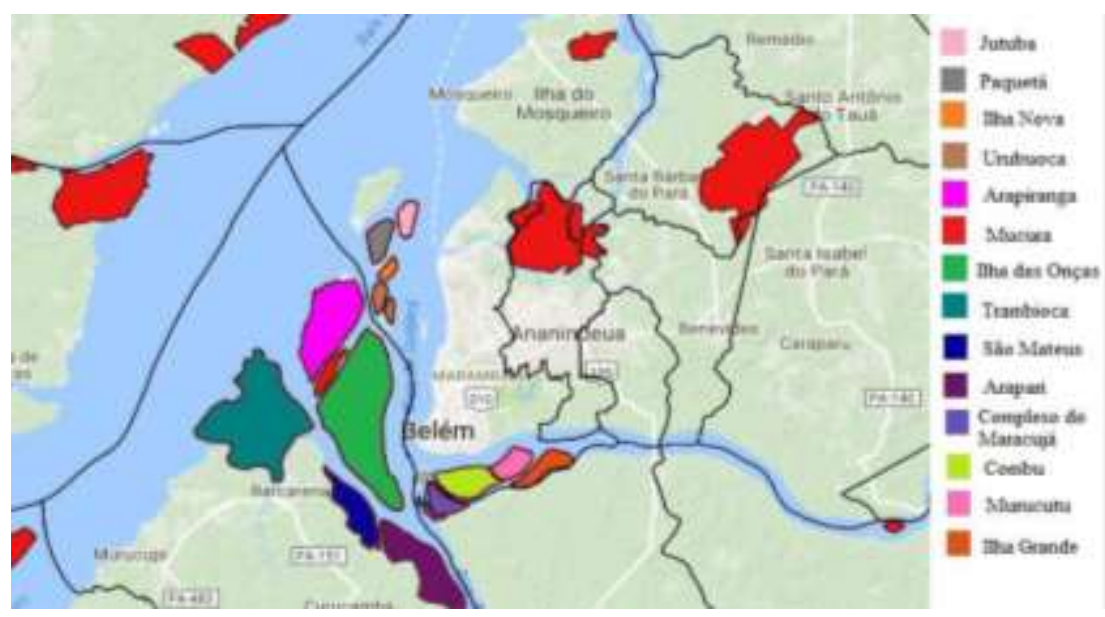

Fonte: Mapas Ipea-I3Geo (2014). 
Uma parte substantiva dos municípios de Belém e Ananindeua, constituem-se sistemas insulares. Em Belém, são 39 ilhas que, à exceção de Mosqueiro, Caratateua (Outeiro) e Cotijuba, possuem áreas urbanizadas e maior população, são ilhas consideradas densamente florestadas e de baixa densidade populacional. Nestas ilhas habitavam em 2000 cerca de 8.260 pessoas segundo o IBGE (Silva, 2011), como mostra a tabela de $\mathrm{n}^{\circ}$ 01. No município de Belém, as ilhas são distribuídas em quatro blocos (Tabela 1).

Tabela 1. Distribuição das ilhas.

\begin{tabular}{cccc}
\hline Norte & $\begin{array}{c}\text { Centro- } \\
\text { Leste }\end{array}$ & $\begin{array}{c}\text { Extremo } \\
\text { Oeste }\end{array}$ & Ao Sul \\
\hline Mosqueiro & $\begin{array}{c}\text { Caratateua - } \\
\text { Outeiro }\end{array}$ & Cotijuba & Murutucã \\
\hline Papagaio & $\begin{array}{c}\text { Ilha Nova } \\
\text { (Coroinha) }\end{array}$ & $\begin{array}{c}\text { Combu } \\
\text { (Marineira) }\end{array}$ \\
\hline Cunuari & Jutuba & Ilhinha \\
\hline São Pedro e Conceição & Tatuoca & Grande \\
\hline & Urubuoca & Murutucã \\
\hline \multicolumn{3}{c}{ Paquetá-açú } \\
\hline & Patos/ Mirim \\
& Cintra \\
(Maracujá & \\
\hline
\end{tabular}

Fonte: Tabela com informação Instituto Peabiru (2015).

Bloco Norte: Representa um contraste de ilhas, uma com a urbanidade bem avançada e pouco adensamento de florestamento, como a ilha de mosqueiro e as outras bem isoladas e intocáveis, como as ilhas do papagaio e a São Pedro e Conceição.

Bloco Centro-Leste: A ilha de Caratateua, mas conhecida como ilha do Outeiro, tem várias praias e é bem visitada nos meses de férias devido ser mais próxima do centro da cidade.

Bloco Extremo Oeste: São ilhas mais afastadas da cidade, para acessá-las tem que pegar um barco que transportam quem mora na ilha e ate mesmo quem vai curtir um dia de praia com a família.

Bloco Sul: São ilhas mais afastadas da cidade, para acessá-las tem que pegar um barco, chamados popularmente de "popopo". Algumas delas são pontos turísticos com referencia culinários.

Existem várias comunidades ribeirinhas isoladas e muitas vezes com pequenas aglomerações geralmente nas margens dos rios e canais.

Foram pesquisados pelo instituto Peabiru que constatou em suas diferentes visitas às ilhas de Jutuba e Cotijuba a existência de diversas comunidades numa mesma ilha. À exceção de Mosqueiro e Ilhas do Norte, que são parte do Distrito Administrativo de Mosqueiro (DAMOS), as Ilhas de Belém estão sob a Administração do Distrito Administrativo de Outeiro (DAOUT).

O rio lidera e engloba a vida regional, de todo o sistema de enchente e inundações periódicas, preparando grande parte das terras e das florestas, possibilitando a circulação, do comercio e a sociabilidade, liderando a condensação e a repartição do elemento humano na passagem. Nota-se que os ribeirinhos vivem da ilha, pois suas atividades realizadas diariamente são de cunho extrativista (coleta de frutos e semente e plantio de espécie nativa), pesca artesanal e a criação de animais domésticos (Figura 5). 
Figura 5. Ribeirinhos.

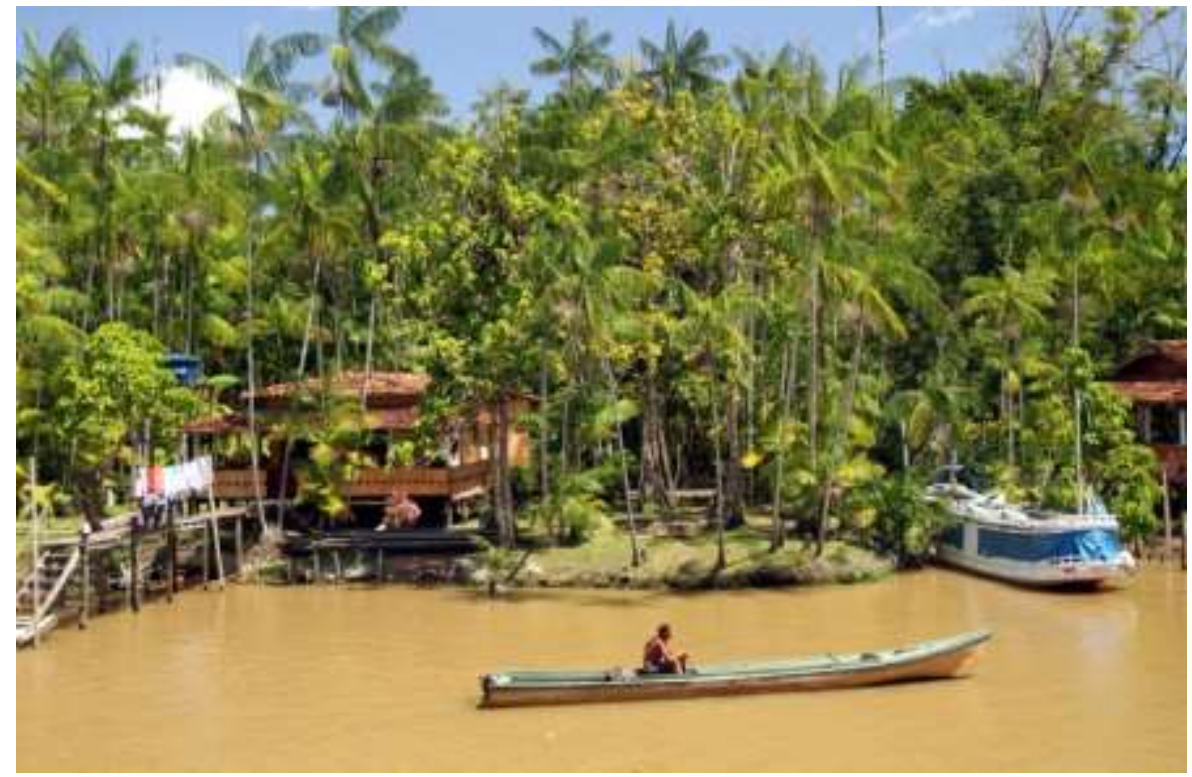

Fonte: www.synod.va/content/sinodoamazonico/pt/noticias/ihas-de-belem--pa---natureza-preservada-e-vida-para-os-ribeirinh.html (2018).

A sobrevivência dessas pequenas populações ribeirinhas, situadas nas ilhas do município de Belém que apresentam umas especificidades sociais, que agregam características econômicas, culturais e ambientais próprias. Uma forma instrumentada pela resistência do saber popular resistindo com a vivencia que reatualizam as relações de trabalho e de forma de produção. Eles são dependentes do Estado e das políticas públicas para manter os costumes de seus antepassados, dando suporte com educação, água potável e melhores condições de vida.

\section{Considerações Finais}

Belém é um lugar riquíssimo de belezas naturais, mas pobre em outros quesitos, apesar disso é possível restaurar seus espaços, resgatar suas memorias e guardar seus traços na história, podem observar toda história envolvendo sua colonização e expansão econômica da região, em especial Belém. Como essa exploração da região, se transformou espacialmente a cidade e a mistura de culturas, pode modificar o estado todo, com uma diversidade que surpreende ao passar do tempo.

Podem observar que são muitas ilhas nas margens das bacias do Guajará, e várias comunidades vivendo nessas pequenas ilhas. A população ribeirinha com os costumes tradicional tenta vencer o descaso do poder público, do sistema capitalista e inúmeros problemas, de quem mora nas ilhas relatam. Mesmo com diversos problemas a maioria das pessoas que moram em ilhas juntos com a natureza amazônica, não pensam em sair das suas casas para aventurar algo novo na capital, ao contrário, preferem ficar tentando e se adaptando na questão econômica a uma vida melhor.

Com isso, é importante ressaltar que a mais dramática constatação se refere à precariedade da infraestrutura pública e não apenas relacionada à produção. Seja do ponto de vista social, como econômico, todos dependem da capital, seja do porto de Icoaraci, seja dos portos ao longo de Belém, ou para as ilhas de Ananindeua, de portos nos furos.

Em um cenário onde a área urbana apresenta forte crescimento econômico e, consequente, melhoria da qualidade de vida, a exclusão histórica dos ribeirinhos se torna mais clara - especialmente em questões básicas, como acesso a água potável, energia, saúde, transporte. Mesmo questões básicas não foram solucionadas, como a da água potável. Para Meirelles Filho (2015), muitas comunidades despendem grandes somas de recursos, apenas para ter água para beber, como é o caso das comunidades na Ilha de cotijuba. 
Research, Society and Development, v. 10, n. 3, e14610313173, 2021

(CC BY 4.0) | ISSN 2525-3409 | DOI: http://dx.doi.org/10.33448/rsd-v10i3.13173

Com base nos assuntos abordados no decorrer do trabalho, recomenda-se que sejam realizadas mais pesquisas em comunidades similares às apresentadas nesta pesquisa, objetivando que as mesmas ganhem mais espaço e reconhecimento, o que, além de disseminar mais suas culturas e costumes, ganhem também mais atenção do Estado.

\section{Referências}

Arenz, Karl Heinz. (2000). Filhos e Filhas do Beiradão. Santarem: fit.

BNDES. (2019). http://www.fundoamazonia.gov.br/pt/projeto/Ilhas-de-Belem/\#top.

Companhia de Habitação do Estado do Pará - COHAB. http://www.cohab.pa.gov.br.

Das Neves B. A. J. (2016). Entre os Rios e as favelas. o PAC nas baixadas da bacia das estrada Nova e na comunidade de Taboquinha.

Dallari, A. A. \& Ferraz S. (2014). "Estatuto da Cidade.” In: Estatuto da Cidade. São Paulo: Malheiros Editores, 9.

Caracterização e Quadros de Análise Comparativa da Governança Metropolitana no Brasil: arranjos institucionais de gestão metropolitana. (2015). Relatório de Pesquisa, Rio de Janeiro: IPEA.

Gonçalves, L. S. (2015). Avaliação de qualidade de habitação de interesse social por meio de estudo de caso de mutirão auto gerido: Inserção Urbana, Implantação e Unidades Habitacionais. Revista Nacional de Gerenciamento de Cidades, 3(22).

Marques, E. (2007). Assentamentos precários no Brasil urbano. Ministério das Cidades/CEM. https://direito.mppr.mp.br/arquivos/File/relatorioassentamentos-precatorios-no-brasil-urbano.pdf

Meirelles, J. (2015). Belém Ribeirinha. Instituto Peabiru, 21.

Pereira, A. S. et al. (2018). Metodologia da pesquisa científica. UFSM. https://repositorio.ufsm.br/bitstream/handle/1/15824/Lic_Computacao_MetodologiaPesquisa-Cientifica.pdf?sequence $=1$.

Ponto, J. P. X. (2013). Bem-estar urbano em Belém: extensa periferia precária. https://www.observatoriodasmetropoles.net.br/bem-estar-urbano-em-belemextensa-periferia-precaria/.

Ribeiro, D. (1997). O povo brasileiro. companhia das letras.

Secretaria Municipal de Coordenação Geral do Planejamento e Gestão,(SEGEP). (2007). Cartilha de revisão do Plano Diretor Urbano de Belém. Retirado de: lwww.belem.pa.gov.br.

SEHAB. (2004). Projeto social da SEHAB. http://www.belem.pa.gov.br/app/c2ms/v/?id=9.

Silva, R.O. (2011). Pesquisa de Cadeias de Valor Sustentáveis e Inclusivas: Açaí. instituto Peabiru, 64.

Sintese e atualização, Belém: Governo do Pará. (2014). Sintése e atualização, do Plano Estadual de Habitação de Interesse Social. 